NUKHBATUL 'ULUM : Jurnal Bidang Kajian Islam

Vol. 4, No. 1 (2018) : Hal. 97-104

Website: https://journal.stiba.ac.id

ISSN : 2685-7537 (online) 2338-5251 (Printed)

\title{
FAKTOR-FAKTOR KEBOLEHAN $A L$-MUBTADA BERUPA ISIM NAKIRAH DALAM KAJIAN ILMU NAHWU
}

\section{Ronny Mahmuddin}

Sekolah Tinggi Ilmu Islam dan Bahasa Arab (STIBA) Makassar,

Jl. Inspeksi PAM Manggala-Antang Makassar

E-Mail: ronnymahmuddin@gmail.com

\begin{tabular}{ll}
\hline Keywords : & ABSTRACT \\
\cline { 2 - 3 } Ilmu Nabwu, al-Mubtada & One of the subjects in the study of Nabwu Knowledge is al-Mubtada. \\
,al-Khabar, Isim Makerifah, & Al-Mubtada is one of the important elements in a sentence. One cause \\
Isim Nakirah & of imperfect sentence is due to unfamiliarity with al-Mubtada' and the \\
& absence of al-Mubtada'. Beginner students in studying Nabwu only \\
& understand that al-Mubtada has to be in a form of Ism Ma'rifah and \\
& not in a form of Ism Nakirah. However, if it is further analyzed, al- \\
Mubtada in a form of Ism Nakirah can be found. Therefore, the \\
author of this paper attempted to explain about "Conditions on al- \\
Mubtada in a form of Ism Nakirah in the study of Nahwu \\
knowledge". Before explaining further on this subject, the author \\
previously mentioned definitions of al-Mubtada, kinds of al-Mubtada, \\
and the grammar of al-Mubtada. Therefore, the readers may achieve \\
comprehensive understanding of al-Mubtada in the study of Nabwu \\
Knowledge. This paper is analyzed by applying literature method. \\
Keyword: Nabwu Knowledge, al-Mubtada, al-Khabar, Ism Ma'rifah, \\
Ism Nakirah.
\end{tabular}




\section{PENDAHULUAN}

Sesungguhnya Bahasa Arab adalah bahasa yang dipilih oleh Allah untuk agama ini (Islam). Tidak perlu diragukan oleh siapa pun bahwa Bahasa Arab dan Ilmu-ilmu yang berkaitan dengannya termasuk salah satu dari ilmu-ilmu Islam diposisikan sebagai lisan bagi anggota tubuh manusia. Tidak salah jika kita katakan bahkan Bahasa Arab merupakan jantung bagi tubuh manusia, karena ia adalah lisan (bahasa) Islam yang paling tinggi, dengannya diturunkan al-Qur'an alKarim, sebagaimana Allah Ta'ala berfirman Q.S. Yusuf /12: 2.

\section{Terjemahnya: \\ "Sesunggubnya \\ Kami \\ menurunkannya berupa al-Qur'an agar kamu mengerti".}

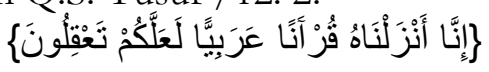

Bahasa Arab merupakan bagian dari agama, sebagaimana yang dikatakan oleh Ibnu Taimiyah r.a: "Telah diketahui bahwa hukum mempelajari Bahasa Arab dan mengajarkannya adalah fardhu kifayah". ${ }^{2}$ Lebih lanjut Ibnu Taimiyah r.a berkata: "Bahasa Arab adalah syiar Agama Islam dan orang Islam. Dan keragaman bahasa adalah salah satu syiar yang terbesar bagi seluruh umat, dengannya mereka memiliki karakteristik tersendiri". 3

Prof. DR. Azhar Arsyad, M.A. menuturkan:

${ }^{1}$ Kementian Agama, Al-Qur'an dan Terjemahnya. (Solo: PT. Tiga Serangkai Pustaka Mandiri, 2007), h. 235.

${ }^{2}$ Abdul Rahmān bin Ibrahīm al-Fauzān dkk, al-Arabiyyah Baina Yadaika (Cet. I; Riyāḍ: alArabiyah Lil Jami'', 1423/2002), h. j.

${ }^{3}$ Abdul Rahmān bin Ibrahīm al-Fauzān dkk, al-Arabiyyah Baina Yadaika, h.d.

${ }^{4}$ Azhar Arsyad, Bahasa Arab dan Metode Pengajarannya, (Cet. II; Yogyakarta: Pustaka Pelajar, 2004), h. 1.
Bahasa ini digunakan secara resmi oleh kurang lebih 20 negara. Dan karena ia merupakan bahasa kitab suci dan tuntunan agama umat Islam, maka tentu saja ia merupakan bahasa yang paling besar signifikansinya bagi ratusan juta Muslim sedunia, baik yang berkebangsaan Arab maupun bukan. ${ }^{4}$

Syu'bah r.a berkata:

"Pelajarilah Bahasa arab karena Bahasa Arab itu akan menambah (ketajaman) daya nalar".

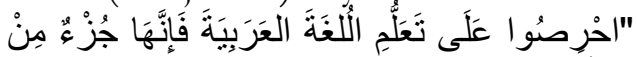

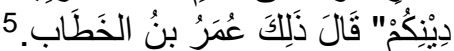

Umar bin al-Khaththab r.a berkata:

"Hendaklah kalian semua tamak mempelajari Bahasa Arab karena Bahasa Arab itu merupakan bagian dari agama kalian".

Imam Syafi'I berkata:

"Manusia bodoh dan berselisih hanyalah karena mereka meninggalkan Bahasa Arab dan kecendrungan mereka kepada Bahasa Aristoteles".

Beliau juga mengatakan:

"Seyogyanya setiap orang mampu mempelajari Bahasa Arab karena ia adalah Bahasa yang paling utama"?

Sebagaimana yang disebutkan oleh Imam Ibnu Taimiyah.Salah satu cabang ilmu Bahasa Arab yang paling penting adalah Ilmu Nahwu. Semua

\footnotetext{
${ }^{5}$ Azhar Arsyad, Bahasa Arab dan Metode Pengajarannya, h. 7.

'Imam Syafi'l, dinukil oleh Dr. Abdur Rahman al-Fauzan, dkk., al-Arabiyyah Baina Yadaika, h. j.

7Imam Syafi'l, dikutip oleh Ibnu Taimiyah, Iqtiọa al-Śirātal Mustaqīm Li Mukhalafah al-Așhāb al-Jahīm, (Riyāḍ: Dār alAșhimah, 1419), h. 464.
} 
ilmu membutuhkan Ilmu Nahwu, oleh karenanya, para ulama salaf telah memberikan dorongan kepada kita untuk mempelajari ilmu nahwu. Bahkan salah seorang dari mereka menyuruh untuk mempelajari ilmu nahwu sebagaimana seseorang mempelajari kewajiban-kewajiban dan sunnah-sunnah.

Salah satu pembahasan dalam kajian Ilmu Nahwu adalah al-Mubtada. Al-Mubtada adalah salah satu unsur bagian kalimat yang sangat penting. Atau dikatakan sebagai salah satu pokok kalimat. Oleh karena itu, sangat penting untuk diketahui tentang fungsi al-mubtada dalam sebuah kalimat. Salah satu penyebab kalimat tidak sempurna adalah karena mubtada tidak diketahui atau tidak ada dalam kalimat. Perlu juga diketahui bahwa orang yang sudah mempelajari ilmu nahwu bagi pemula khususnya terkadang hanya mengetahui bahwa al-mubatada itu harus dari isim (kata) ma'rifah dan tidak boleh isim nakirah, karena ciri-ciri mubtada adalah harus isim makrifah. Tapi jika kita pelajari lebih jauh dan mendalam yang terdapat dalam kitabkitab nahwu yang lebih luas, maka kita dapatkan bahwa ada juga mubtada yang berasal dari isim nakirah bukan makrifah.

Berangkat dari persoalan ini, maka pemakalah tertarik untuk mengkaji lebih dalam pada makalah ini tentang faktor-faktor apa saja yang menyebabkan bolehnya mubtada berasal dari isim nakirah beserta contoh-contohnya dalam sebuah kalimat. Bahkan pemakalah mencoba menyebutkan contoh-contoh mubtada berupa isim nakirah dalam ayat-ayat alQur'an. Namun sebelumnya,

${ }^{8}$ Mushtafā al-Gulayainī bin Muhammad Sālim, Jāmi' al-Durūs al-'Arabiyyah (Cet.l; Kairo: Dār Ibnu al-Jauziī, 2010), h. 373. pemakalah menyebutkan sekilas tentang definisi al-Mubtada, hukumhukumnya dan jenis-jenisnya agar pembaca dapat memiliki wawasan tentang permasalahan al-mubtada dalam ilmu nahwu.

Berdasarkan latar belakang di atas, maka yang menjadi rumusan masalah dari makalah ini adalah:

1. Apa yang definisi al-Mubtada?

2. Bagaimana hukum alMubtada?

3. Berapa jenis al-Mubtada?

4. Apa faktor-faktor dibolehkannya al-mubtada berupa isim nakirah?

\section{PEMBAHASAN}

\section{Definisi al-Mubtada ${ }^{8}$}

Al-Mubtada adalah isim (kata benda) yang dengannya dapat terbentuk jumlah mufidah (kalimat sempurna). Al-Mubtada selalu berpasangan dengan al-Khabar, karena kaliimat sempurna tidak bisa terbentuk tanpa adanya khobar. Contohnya:

الحَقُّ مَنْصُوْرُ

Artinya:

"Kebenaran itu akan menang"

Al-Haq (الحَقُّ): al-Mubtada dan manshur (مَنصصُوْرِ):al-Khabar. Dengan kedua kata ini (al-Mubtada dan alKhabar), maka dapat terbentuk jumlah mufidah (kalimat sempurna).

Dalam Bahasa Indonesia, mubtada adalah kata yang diterangkan, sedangkan al-khabar adalah kata yang menerangkan. Pada contoh di atas menunjukkan bahwa al-haq adalah kata yang diterangkan (mubtada) sedangkan manshur adalah kata yang menerangkan (khabar). Mubtada dan khabar dalam ilmu nahwu disebut 
jumlah ismiyah (kalimat yang didahului oleh isim).

\section{Hukum al-Mubtada}

Al-Mubtada memiliki lima hukum, yaitu sebagai berikut:

a. Al-Mubtada wajib dalam keadaan rafa', contoh: البَيْتُ كَبِيرٌ =artinya: Rumah itu besar.

Al-Baitu (الَيَبْنُ:): al-Mubtada dalam keadaan rafa' (dhommah). Jadi al-baitu harus dalam keadaan rafa'. Tidak boleh dikatakan al-baita (dalam keadaan nashob berharakat fathah) atau tidak boleh dikatakan al-baiti (dalam keadaan jar dengan harakat kasrah).

b. Al-Mubtada wajib isim ma'rifah bukan isim nakirah.

Contoh: مَحِمَّدُ رَسُوُُْْ الله

Muhammad (مُحَمَّدُدُ dengana isim ma'rifah.

c. Bolehnya al-Mubtada dihapuskan jika ada dalil yang menunjukkannya. Contoh:

Jika ada yang bertanya: كَيْنَ سَعِيْدִِ

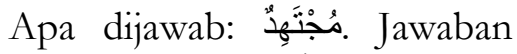
lengkapnya adalah هُوَ مَجْنَهِهِ

Tapi boleh dihapuskan mubtadanya dan yang disebutkan hanya khabarnya saja. Ini dibolehkan karena ada dalil yang menunjukkan bahwa mubtada dihapuskan, yaitu كَيْنَ سَعِيْيُ ؟

d. Al-Mubtada wajib dihapuskan, jika khabarnya adalah mashdar yang menggantikan fi'ilnya (kata kerjanya). Contoh:

adapun yang

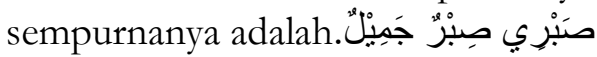
صَبْرِي adalah mubtada, tapi pada kalimat ini boleh wajib

${ }^{9}$ Mushtafa al-Gulayainī, jāmi' al-Durūs al-Arabiya, h. 373-376.

${ }^{10}$ Abdul Azīz bin Muhammad alFantukh, dkk, Tażīb Syarh Ibni Aqīl Li Alfiyah Ibni dihapuskan mubtadanya karena khabarnya adalah mashdar yang menggantikan fi'ilnya.

\section{Jenis-jenis al-Mubtada}

Ibnu Malik menyebutkan bahwa almubtada ada dua jenis ${ }^{10}$, yaitu:

1). Mubtada yang mempunyai khabar.

Contohnya: مُحَمَّدُ قََائمِ

Penjelasan:

Muhammad (مُحَمَّدم): Mubtada'.

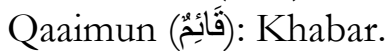

Pada contoh di atas dapat kita lihat bahwa ada kesesuaian antara mubtada dan khabar, yaitu mubtada berbentuk mufrad dan khabar pun harus berbentuk mufrad.

Contoh mubtada yang memiliki khabar adalah contoh-contoh yang biasa kita jumpai dalam kalimat atau di teks-teks bacaan atau cerita atau percakapan sehari-hari.

\section{2). Mubtada Yang Mempunyai Fa'il} Yang Menempati Kedudukan Khabar (Fa'il Sadda Masadda A1Khabar). Dengan istilah bahasa arabnya disebut fa'il sadda masadda alkhabar.

Contohnya: أَسَارٌ هَذَانِ؟

Penjelasan I'rab:

al- Hamzah (I) : Huruf yang digunakan untuk bertanya.

Saarin (سآرٍ): Mubtada.

Haadzaani (هذان): Fa'il yang menempati kedudukan khabar dan tidak bisa dikatakan sebagai khabarul mubtada' karena mubtada' di sini bentuknya mufrad sedangkan hadzaani bentuknya mutsanna. Sebagaimana kaidah nahwu disebutkan bahwa khabar harus mengikuti mubtada dalam

Mālik, Vol. I (Riyāọ: Maktabah al-Malik Fahd alWațaniyah, 1418), h. 149-150. 
segala hal seperti jika mubtada mufrad maka khabar harus mufrad. Sedangkan pada contoh di atas mubtada dalam bentuk mufrad maka khabar mestinya khabar juga harus mufrad, tapi justru hadzani dalam bentuk mutsanna. Ini menunjukkan bahwa hadzani adalah bukan khabarul mufrad akan tetapi hadzani adalah sebagai fa'il yang menempati kedudukan khabar (fa'il sadda masaddal khabar). Demikian itu karena 'amilnya berupa sifat yaitu saarin (isim fa'il). Sebagaimana dalam kaidah bahwa isim fa'il ber'amal (berfungsi) sama dengan fi'ilnya.

Mubtada yang memiliki fa'il yang menempati kedudukan khabar, maka jarang kita temukan dalam sebuah kalimat atau teks bacaan atau sebuah percakapan sehari-hari.

Yang menjad faktor bolehnya sifat menjadi mubtada yang mempunyai fa'il yang menempati kedudukan khabar diantaranya adalah huruf istifham (kata tanya) atau nafiy (kata yang menafikan),

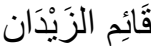

seperti contoh: أَ قَائعِ الزَيدَان وَمَا

Contoh di atas kata sifat (qaaim) sebagai mubtada' yang mempunyai fa'il (az-zaidani) yang menempati kedudukan khabar karena mubtada tersebut bersandar pada kata istifham (kata tanya), begitu pula kata sifat (qaaim) sebagai mubtada' karena bersandar pada kata penafian (nafiy).

Dipertegas oleh DR. Abduh arRajihiy bahwa sifat ini ketika menjadi mubtada' maka ia membutuhkan isim marfu' setelahnya, yang mana isim tersebut dii'rab sebagai fa'il setelah isim fa'il dan dii'rab naib fa'il setelah isim maful, dan mubtada tersebut harus

${ }^{11}$ Abduh Ar-Rajihī, al-Tațbīq al-Nahwī (Cet. II; Riyād: Maktabah al-Mā'arif Li al-Nasyr wa al-Tauzi’', 1432), h. 89. bersandar pada huruf nafiy dan istifham ${ }^{11}$.

Contoh: مَا نَاجِحُ المُهُهِلْ

Penjelasan I'rab:

Maa (م): Huruf Nafiy

Naajihun (نَاجِح): Mubtada.

Al-Muhmilu (المُهْمِلُّ): Fa'il sadda masadd al-khabar.

Disebutkan oleh Musthofa alGhulayaini bahwa sifat tersebut berkedudukan sama dengan fi'il (kata kerja). Oleh karena itu kata sifat itu tidak dimutsannakan, dijamakkan, tidak disifati, tidak ditashgir dan tidak dimakrifahkan. ${ }^{12}$

Pendapat ulama nahwu dari kota Basrah mengatakan bahwa sifat pada contoh di atas tidak bisa menjadi mubtada' kecuali jika sifat tersebut (berupa nakirah) bersandar pada huruf nafiy (huruf yang menafikan) atau huruf istifham (kata tanya), sebagaimana yang telah dicontohkan d atas.

Sedangkan ulama nahwu dari kota Kufah mengatakan bahwa sifat (berupa isim nakirah) bisa menjadi mubtada' meskipun tidak bersandar pada huruf nafiy dan istifham.

Conthnya: قَائعٌ الزَيْيَدَان

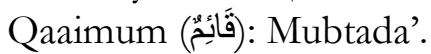

Az-Zaidani (الزَيْدَان): Fa'il sadda masadda al-khabar.

\section{Faktor-Faktor}

Bolehnya Mubtada' Berupa Isim Nakirah.

Pada dasarnya mubtada' adalah isim ma'rifah, akan tetapi terkadang bisa berupa isim nakirah tapi dengan syarat. Ibnu' Aqil menyebutkan enam faktor dibolehkannya mubtada berupa isim nakirah, sebagai berikut:

1). Jika Khabar mendahului mubtada' dalam kalimat yaitu

${ }^{12}$ Musțafā à̃ al-Ghulayainī bin
Muhammad Sālim, Jāmi' al-Durūs al-'Arabiyyah,
h. 380.




\author{
khobar berupa zhorf (kata \\ keterangan tempat atau waktu) atau \\ jar wa majrur. \\ Contoh: فِي الَََّارِ رَجْلُّ \\ Penjelasan I'rab: \\ Fi addari (فِي الدَّارِ): Jar wa Majrur \\ sebagai khobar muqaddam \\ (didahulukan).
}

Rojulun (رَجُجُجُ): Mubtada' muakhkhor (berupa isim nakiroh).

Pada contoh di atas menunjukkan bahwa mubtada berupa isim nakirah bukan ma'rifah. Hal ini dibolehkan karena mubtada didahului oleh khabar yang berupa jar wa majrur.

Aflikasi penggunaan mubtada berupa isim nakiroh dalam al-Qur'an. ${ }^{13}$

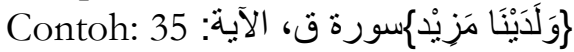

Dalam ayat di atas menunjukkan bahwa mubtada dibolehkan berupa isim nakiroh. Hal ini dikarenakan mubtada tersebut didahului oleh zhorf makan (keterangan tempat).

Begitu pula dalam al-Qur'an surah al-

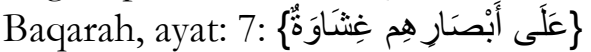

Ayat ini juga menunjukkan kebolehan mubtada berupa isim nakiroh dikarenakan adanya jar wa majrur yang mendahului mubtada.

2). Jika Mubtada didahului oleh isim istifham (kata tanya).

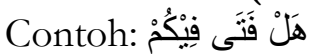

Penjelasan I'rab:

Hal (هَل): Isim Istifham.

Isim nakiroh (fatan) adalah mubtada'.

Fii Kum (فيكُم): Syibhul Jumlah (Khabar).

Fatan adalah mubtada beruapa isim nakiroh. Hal ini dibolehkan karena isim nakiroh tersebut didahului oleh isim istifham yaitu bal.

\footnotetext{
${ }^{13}$ Imam Abū Muhammad Abdullāh Jamaluddīn Ibnu Hisyām al-Anṡarī, Audah al-
}

Aflikasinya dalam al-Qur'an, seperti pada surah al-Naml, ayat: 60-64:

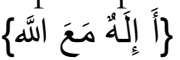

Penjelasan: pada ayat ini menunjukkan bahwa mubtada' boleh berupa isim nakirah karena didahului oleh huruf istifham (kata tanya).

3). Jika Mubada' didahului oleh huruf nafiy (huruf yang meniadakan).

Contoh: مَا خَلَّ لَنَانَا

Penjelasan I'rab: Kata khillun adalah mubtada yang berupa isim nakiroh. Lanaa adalah khobarnya. Hal ini dibolehkan karena isim nakiroh tersebut didahului oleh huruf nafiy yaitu maa.

4). Mubtada yang berupa nakiroh disifati oleh sesuatu.

Contoh: رَجُلُْ مِنْ الكَرَرِ عِنْدَنَا

Penjelasan I'rab: Rojulun adalah mubtada yang berupa isim nakiroh. Hal ini dibolehkan karena isim tersebut disifatkan oleh sesuatu yang datang setelahnya yaitu minal karom. Sedangkan 'indanaa adalah khabarnya.

Aflikasi penggunaannya dalam al-Qur'an yaitu pada surah al-Baqarah, ayat: 221 .

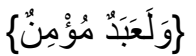

Penjelasan I'rab: Kata 'abdun adalah mubtada yang berupa isim nakiroh. Ini dibolehkan karena isim tersebut disifati oleh kata setelahnya yaitu mukmin.

5). Jika Mubtada menjadi 'amil (berfungsi sebagai kata kerja),

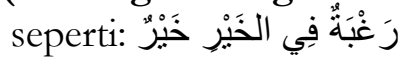

Penjelasan I'rab: Kata raghbatun adalah mubtada berupa isim nakiroh. Ini dibolehkan karena isim tersebut menjadi amil bagi isim setelahnya yaitu fil khair. Sedangkan khairun adalah khabarnya. Maktabah al-Așriyyah, 1417), h. 184. 


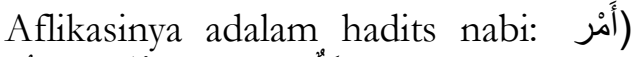

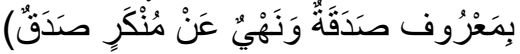

Penjelasan I'rob: Pada hadits di atas menunjukkan kebolehan isim nakiroh yaitu amrun sebagai mubtada karena isim nakiroh tersebut berfungsi sebagai 'amil yang berfungsi sebagai kata kerja.

6). Mubtada berupa isim nakiroh jika berupa mudhof (kata yang menyandari kata setelahnya). Contoh: عَلُْ برِ يَزِيْنُ

Penjelasan I'rob: Kata 'amal di sini adalah mubtada meskipun nakiroh. Hal ini dibolehkan karena 'amal berupa isim mudhof kepada isim setelahnya yaitu birrin. Sedangkan yaziinu adalah khabarnya.

Aflikasinya dalam sebuah hadits,

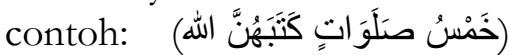

Penjelasan I'rob: Khomsu adalah isim nakiroh yang menjadi mubtada. Ini dibolehkan karena khomsu dimudhofkan kepada isim setelahnya yaitu sholawaatin.

\section{PENUTUP}

1). Al-Mubtada adalah isim (kata benda) yang dengannya dapat terbentuk jumlah mufidah (kalimat sempurna), contoh: محمد مجته = Muhammad rajin. Muhammad adalah sebagai mubtada, dan mujtahid adalah khabarnya.

2). Al-Mubtada memiliki lima hukum, yaitu mubtada wajib rafa', mubtada wajib ma'rifah, mubtada boleh dihapuskan jika ada dalil yang menunjukkannya dan mubtada wajib dihapuskan jika khabarnya adalah mashdar yang menggantikan fi'ilnya (kata kerjanya).

3). Mubtada ada dua jenis, yaitu:

a. Mubtada yang memiliki

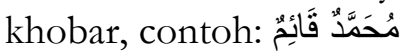

b. Mubtada yang memiliki fa'il yang menempati kedudukan khabar (fa'il sadda masadda al-khobar). Contoh: I

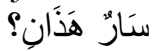

4). Ada enam faktor dibolehkannya mubtada berupa isim nakiroh, yaitu:

a. Khabar mendahului mubtada' dalam kalimat yaitu khobar berupa zhorf (kata keterangan tempat atau waktu) atau jar wa majrur. Contoh:

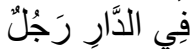

b. Mubtada yang berupa isim nakiroh didahului oleh isim istifham (kata tanya).

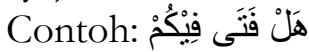

c. Mubada didahului oleh huruf nafiy (huruf yang meniadakan). Contoh: مَا خَلَّ لَنَا

d. Mubtada yang berupa nakiroh disifati oleh sesuatu.

Contoh: رَجُلْ مِنْ الكَرَحِ عِنَدَدَا

e. Mubtada yang berupa isim nakiroh menjadi 'amil (berfungsi sebagai kata kerja), seperti: رَغْبَةُّ فِي الخَيْرِ خَيْر

f. Mubtada berupa isim nakiroh adalah berupa mudhof (kata yang menyandari kata setelahnya). Contoh: عَمَل برِّ يزين

\section{DAFTAR PUSTAKA}

Abdul Hamid, Muhammad Muhyiddin. al-Tubfatus Saniyyah Bisyarbi alMuqaddimah al-Ajurimiyyah, Bairut: al-Maktabah alAshriyah, 2003.

Arsyad, Azhar. Bahasa Arab dan Metode Pengajarannya, Cet. II; Yogyakarta: Pustaka Pelajar, 2004.

Al-Ajlan, Muhammad bin Abdullah. Al-Nabwu-Silsilab Ta'lim alLugah al-Arabiyah. Riyadh: Jamiah al-Imam Muhammad bin Saud, 1994. 
Website: https://journal.stiba.ac.id

ISSN : 2685-7537 (online) 2338-5251 (Printed)

1-Anshory, al-Imam Ibnu Hisyam. Audhabul Masalik Ilaa Alfiyah Ibnu Malik, Bairut: Maktabah al-Ashriyah, 1996.

Al-Fauzan, Abdul Rahman bin Ibrahim dkk. al-Arabiyyah Baina Yadaika, Cet. I; Riyadh: alArabiyah Lil Jami', $1423 / 2002$.

Al-Fantukh, Abd ul Aziz, dkk. Tahdzib syarbi Ibni aqil Lialfiyah Ibni Malik, Riyadh: Maktabah Malik Fahd, 1418.

Hasyim, Dr. Ahmad. Mudzakekirah alNabwi wa al-Shorf, Riyadh: Maktabah Malik Fahd, 1431.

Ibnu Taimiyah, Taqiyuddin. Iqtidha alShiratol Mustaqim Limukbalafati Ashabil Jabim, Riyadh: Darul Ashimah, 1419.

Panitia Pentashih Mushaf al-Qur'an. Al-Qur'an dan Terjemabnya, Solo: PT. Tiga Serangkai Pustaka Mandiri, 2007

Musthofa al-Ghulayainiy Bin Muhammad Salim, Jami' alDurus al-'Arabiyyah. Cet.I; Kairo: Dar Ibni al-Jauziy, 2010.

DR. Abduh Ar-Rajihiy, al-Thatbbiq alNabwiy. Cet. II; Riyadh: Maktabah al-Ma'arif Linnasyri wat Tauzi', 1432. 